\title{
Fetal Hydantoin Syndrome
}

National Cancer Institute

\section{Source}

National Cancer Institute. Fetal Hydantoin Syndrome. NCI Thesaurus. Code C98927.

A teratogenic disorder observed in a newborn or child of a mother who was exposed to phenytoin during pregnancy. Manifestations include dysmorphic craniofacial features, hypoplastic distal phalanges and nails, growth delay and delayed psychomotor development. 